\title{
Communication skills of physicians during patient interaction in an in-patient setting at Tikur Anbessa Specialized Teaching Hospital (TASH), Addis Ababa, Ethiopia, 2009
}

\author{
Daniel Zewdneh ${ }^{1}$, Kifle W/Michael ${ }^{2}$, Sosena Kebede ${ }^{3}$
}

\begin{abstract}
Background: Physician-patient relationship is foremost among the numerous qualities needed for sound patient care. In the Ethiopian clinical setting, a vast majority of patients complain that physicians do not interact with them properly.

Objective: Assess behavior of physicians (verbal and nonverbal) when interacting with patients.

Methods: Randomly selected physicians were observed in doctor-patient interactions in an inpatient setting using a standardized check list at Tikur Anbessa Hospital in November, 2009.Mean comparison of total scores of each category as well as mean interaction and biomedical exam times were made using Pearson's Chi square, and Student's T test.

Results: 211 interactions were observed. 22.7\% were consultants, $49.7 \%$ were residents and $26.5 \%$ were interns. Mean total score of observed behavior ranged from poor to satisfactory across category and showed statistically significant variations. Average interaction time was 7.87 minutes while average biomedical exam time was 5.05 minutes. The means showed a significant variation $(\mathrm{p}=0.001$ at $95 \% \mathrm{CI})$.

Conclusion: The study has shown that there is a reasonable ground to suggest that physician-patient interaction has deficiencies. Due attention should be given to improve communication skills of physicians. [Ethiop. J. Health Dev. 2011;25(1):3-9]

Background

Quite often, the subject of physician-patient interaction and communication is raised as a concern mainly by the public; but health providers themselves (through their associations), health authorities and training institutions have shared this concern through informal communication and exchange of opinion as there is no published work locally.

Our experience as physicians both at teaching and service hospitals shows that no matter how good physicians are at assessing, diagnosing and treating biomedical problems; in as long as they do not heed about imparting their information to the patient and fail to communicate properly; it would be extremely difficult to conclude that patient satisfaction and successful treatment has been achieved.

the patient, and communication about medicine and science (2).

The Kalamazoo I Consensus Statement (3) also outlines seven essential communication tasks that should be part of communication-oriented medical curricula, viz,

1. build the doctor-patient relationship

2. open discussion

3. gather information

4. understand the patient's perspective

5. share information

6. reach agreement on problems and plans

7. provide closure

Practicing physicians usually limit themselves to a few technical questions they want to ask patients, the length of time they give for interaction is often short in terms of
\end{abstract}

The Accreditation Council of Graduate Medical Education/US, (ACGME) defines interpersonal and communication skills as those resulting in effective information exchange and teaming up with patients, families and colleagues (1).

Among perspectives in interpersonal and communication skills, The Macy Initiative in Healthcare Communication identified three broad domains of skills; namely, communication with the patient, communication about patients being able to explain their problems. The pretext behind this is too little time in the face of too much work. In some instances this may be true since physicians find it expedient to do so in a system that requires brevity with little or no attention to personal interaction. According to Colman, countries the world over, are seriously assessing how their doctors communicate with patients. This goes beyond the ability to diagnose and treat health problems and addresses a compassionate and a not- impersonal communication to which no educational system has given a solution as yet (4).

${ }^{1}$ Addis Ababa University, School of Medicine, Tikur Anbessa Hospital, P. O. Box 1176, Tel. +251 115150947 , dzewdneh@yahoo.com;

${ }^{2}$ Jimma University, College of Public Health and Medical Sciences;

${ }^{3}$ Yale School of Public Health, USA. 
Worldwide, over the last two decades, problems around the subject have been studied extensively; and most western medical schools have now incorporated the subject into their curricula (5).

With regard to our local situation, no such studies have been conducted on the behavior and communication of physicians with patients. Various studies world wide have clearly demonstrated that poor interpersonal skill does affect the outcome of healthcare and this fact is well documented in the literature $(4,6-8)$. There are studies which show that patients attach more importance to the communication skill and behavior of physicians than technical abilities as studied from patients' perspectives (9-14). There are also studies that incorporate both physician-defined measures of care and patient satisfaction arguing that both ends of the matter can be seen together while some argue that a single set of measures can be employed to appraise both (15-22).

Unpublished reports of client satisfaction surveys, as part of the Hospital Management Initiatives of the Blueprint Standards of the Federal Ministry of Health, have clearly shown patient dissatisfaction on the problem mentioned above.

Tikur Anbessa Teaching Hospital (TASH), as the oldest and largest medical training center bears the brunt of the problem. The unpublished patient satisfaction report mentioned above shows that it is one of the least favored hospitals by patients. Furthermore, there had never been any attempt to address communication skill problems and revise the curriculum despite the school's reputation for producing clinically renowned physicians at home and abroad.

The rationale for undertaking this research project is, therefore, to stimulate those concerned into a much wider scale of survey by attempting to shade light on the behavior of physicians during their interaction with patients in TASH.

\section{Methods}

Study Area: was Tikur Anbessa Specialized Teaching Hospital, Faculty of Medicine, Addis Ababa University, Addis Ababa. As an 800-bed capacity facility, it is the nation's largest and highest referral hospital.

Study period and design: The study employed a cross sectional design and was carried out in November 2009.

Study population: All physicians (472) practicing and studying at TASH served as source population. These included 98 consultants, 205 residents, 169 interns from all the major clinical departments.

Sample size and technique: A sample size of 384 physicians was selected using stratified random sampling. Sample size was determined based on the assumption that $50 \%$ of physicians would greet patients during interaction with a margin of error of $5 \%$ and $95 \%$ confidence limit.
The sample size obtained was then adjusted for a finite study population with a $10 \%$ contingency yielding a sample size of 233. Finally, probability proportion to size (PPS) was used to select physicians from different categories. Hence, 48 consultants, 101 residents and 83 interns were selected and studied.

Data Collection procedure and management: Data collection was conducted in an inpatient setting, since outpatient departments were overly crowded and would not give a true picture in our set-up. Four evaluators were chosen from among senior ward nurses and trained on observation techniques and how to complete the checklist. Physicians selected for observation as described above were given explanations about the observation after they had consented to participate, but they were not told when the observation would take place to reduce bias. Individuals were observed only once during interaction with patients.

Data Collection Tool: A standardized checklist used by Lehman and adopted from Kraan, (known as the Maastricht checklist) $(17,21)$ was used. The checklist contained 39 items divided into an introduction part (items 1-7), body of the interview (items 8-29), explanations by the physician (items 30-36), and a conclusion part (items 37-39).

Scoring: Since items in the checklist describe objective behaviors, a dichotomous scale ticking yes when behavior is observed, and no if not observed or inapplicable when not relevant as modified from Lehman (17) was used.

Total score in $\%=$ Total No of yes answers $\times 100$ Total No of answers

Rating scale of scores: <50-very poor; 50-60-Poor; 61-70-barely satisfactory; 71-80-Satisfactory and $>80-$ Extremely satisfactory

Scale was modified from the Dutch scale Bensing used (23).

Checklist items were then rated on the devised scale. The checklist has four sections; namely, Observed behaviors and skill of physicians during interaction were calculated as percentage and mean values of the total scores for each category and section of the introduction, body, explanation and conclusion designed in such a way as to show certain characters of behavior, and skill.

The introduction part was meant to measure behavior, courtesy, respect and politeness.

The body part was meant to show and measure concern, empathy, compassion, regarding patients psycho-social problems, emotions both verbally and non- verbally.

The explanation part showed the physician's ability to properly communicate in a language that the patient 
understands and checks whether he or she is making an earnest attempt to make the patient comprehend the details of examination and procedures as well as obtain patients agreement.

The conclusion part was designed to show and measure, the physician's ability to build reassurance, comfort and hope in the patient.

Data entry and Analysis: was performed using SPSS version 13 package. Mean (SD) of total scores were computed for each physician category. Comparison of mean total scores by physician category was computed using Pearson's Chi square and student's t-test. Mean interaction and biomedical exam times were compared using Pearson's chi square test.

\section{Results}

$211(90.9 \%)$ physicians took part in interactions with patients. There were $126(59.7 \%)$ female and 85 (40.3\%) male patients. The majority were in the age group of $21-$ 40 years $(51.2 \%)$.

From the 211 physicians of all categories, the proportion of consultants, residents and interns were $48(22.7 \%)$,
$105(49.7 \%)$ and $56(26.5 \%)$, respectively. General practitioners $(n=4)$ were dropped from this study since they did not fit into the category designed.

Observed communication behavior of physicians during interaction was calculated as total score out of hundred and mean values of these scores for the different categories of the checklist and the total checklist were then rated on the devised scale. The mean of the total scores for each group item of the check list and for each category was rated. The introduction part of the checklist rating for interns was very poor and poor for residents and consultants. Ratings for the body part appeared barely satisfactory for all.

The explanation part was rated as extremely satisfactory for all except the intern category which was rated satisfactory at the cut off range.

The conclusion part showed values that were rated as very poor for interns and residents, barely satisfactory for consultants. The total mean scores of the observed items of the checklist showed ratings of barely satisfactory for residents and consultants while interns were rated as poor (Table 1).

Table 1: Mean of total score for observed behavior by physician category during interaction with patients, Tikur Anbessa Hospital, November 2009

\begin{tabular}{|c|c|c|c|c|c|c|}
\hline \multirow{3}{*}{$\begin{array}{l}\text { Checklist } \\
\text { Items }\end{array}$} & \multicolumn{6}{|c|}{ Category } \\
\hline & \multicolumn{2}{|c|}{ Intern } & \multicolumn{2}{|c|}{ Resident } & \multicolumn{2}{|c|}{ Consultant } \\
\hline & $\begin{array}{l}\text { Mean \% } \\
\text { Score }\end{array}$ & Rating & $\begin{array}{l}\text { Mean \% } \\
\text { score }\end{array}$ & Rating & $\begin{array}{l}\text { Mean \% } \\
\text { Score }\end{array}$ & Rating \\
\hline Introduction part 1-7 & 47.2 & Very poor & 55.61 & Poor & 57.4 & Poor \\
\hline Body part 8-29 & 64 & Barely satisfactory & 70.2 & Barely Satisfactory & 69.5 & Barely Satisfactory \\
\hline Explanation part 30-36 & 74.4 & Satisfactory & 81.3 & Ext. Satisfactory & 85.6 & Ext. Satisfactory \\
\hline Conclusion part 37-39 & 39.8 & Very poor & 45.7 & Very poor & 60.5 & Barely Satisfactory \\
\hline Total & 56.2 & poor & 63.25 & Barely Satisfy & 68.1 & Barely Satisfactory \\
\hline
\end{tabular}

The means total scores for observed behaviors were compared for variations with each category for the different parts of the checklist and the differences noted were not statistically significant $(\mathrm{p}=0.213)$. Whereas the mean total scores of observed behaviors for the three categories were computed for variation using one sample statistics and were significant for interns $(0.006)$, residents (0.004) and consultants (0.002) (Table 2).

Table 2: One sample test of mean scores of physician category during interaction with patients, Tikur Anbessa Hospital, November 2009

\begin{tabular}{|c|c|c|c|c|c|c|}
\hline \multirow{3}{*}{ Category } & \multicolumn{6}{|c|}{ Text Value $=0$} \\
\hline & \multirow{2}{*}{$\mathbf{T}$} & \multirow{2}{*}{ Df } & \multirow{2}{*}{ Sig (2 tailed) } & \multirow{2}{*}{ Mean diff. } & \multicolumn{2}{|c|}{$95 \%$ confidence interval } \\
\hline & & & & & Lower & Upper \\
\hline Consultant & 10.776 & 3 & 0.002 & 68.29750 & 48.1276 & 88.4674 \\
\hline Resident & 8.044 & 3 & 0.004 & 63.21250 & 38.2040 & 88.2210 \\
\hline Intern & 7.143 & 3 & 0.006 & 56.34500 & 31.2412 & 81.4488 \\
\hline
\end{tabular}

Results with regard to the amount of time physicians spent for psycho-social interaction showed that $102(47.4 \%)$ were in the time interval of $5-7$ minutes; $84(39.1 \%)$ in the time interval $8-10$ minutes; $7(3.3 \%)$ fell into 2 - 4 minutes and $11-14$ minutes intervals; and $12(5.6 \%)$ were in the above 14 minute group (Figure1).
Time spent for the biomedical examination showed that 103 physicians $(47.9 \%)$ were in the $5-7$ minute group, with $83(38.6 \%)$ in the $2-4$ minute group, while 21 $(9.9 \%)$ were in the $8-10$ minute group. Only 4 physicians $(1.9 \%)$ were in the above 14 minute group (Figure 2). 


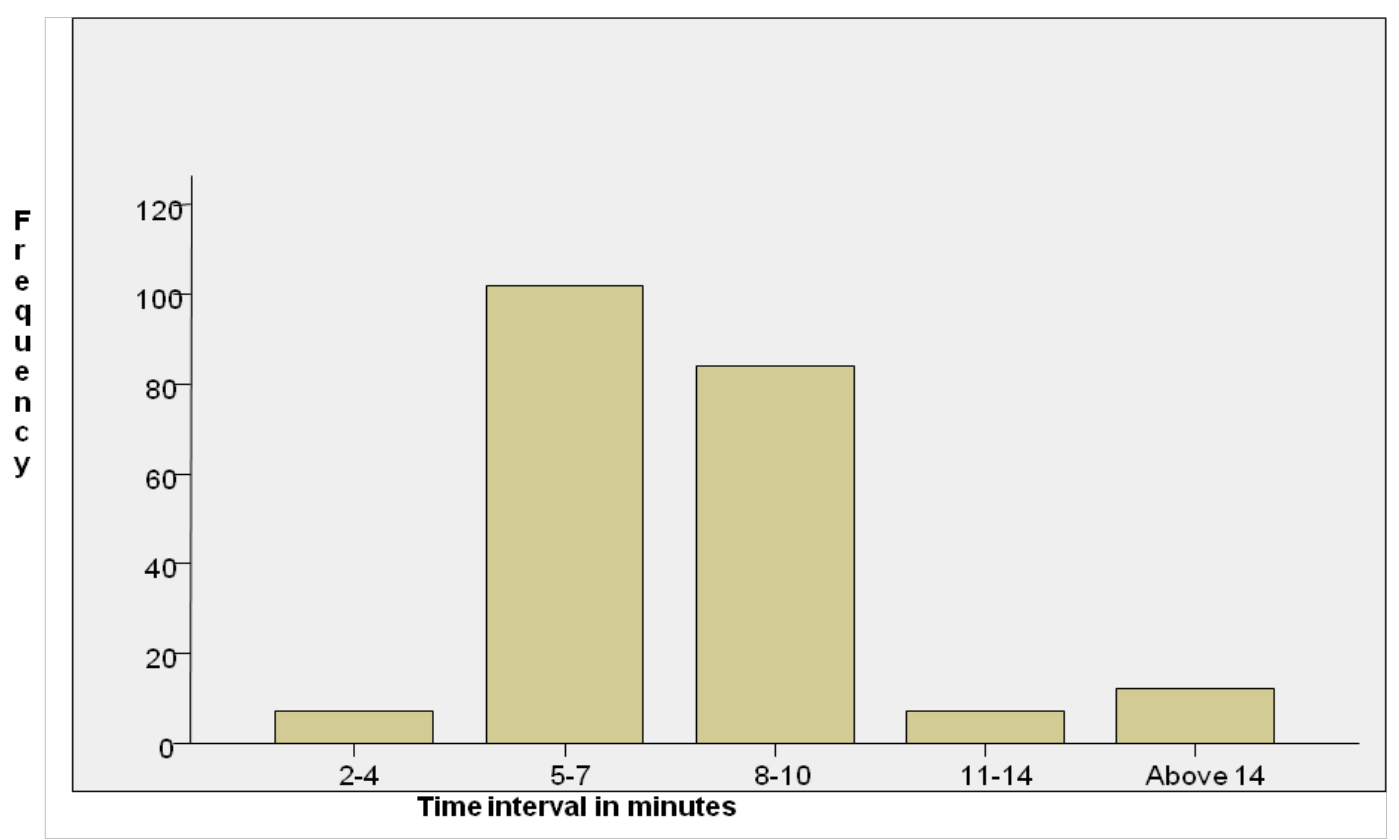

Figure 1: Frequency chart of physician-patient interaction time, Tikur Anbessa Hospital, November 2009

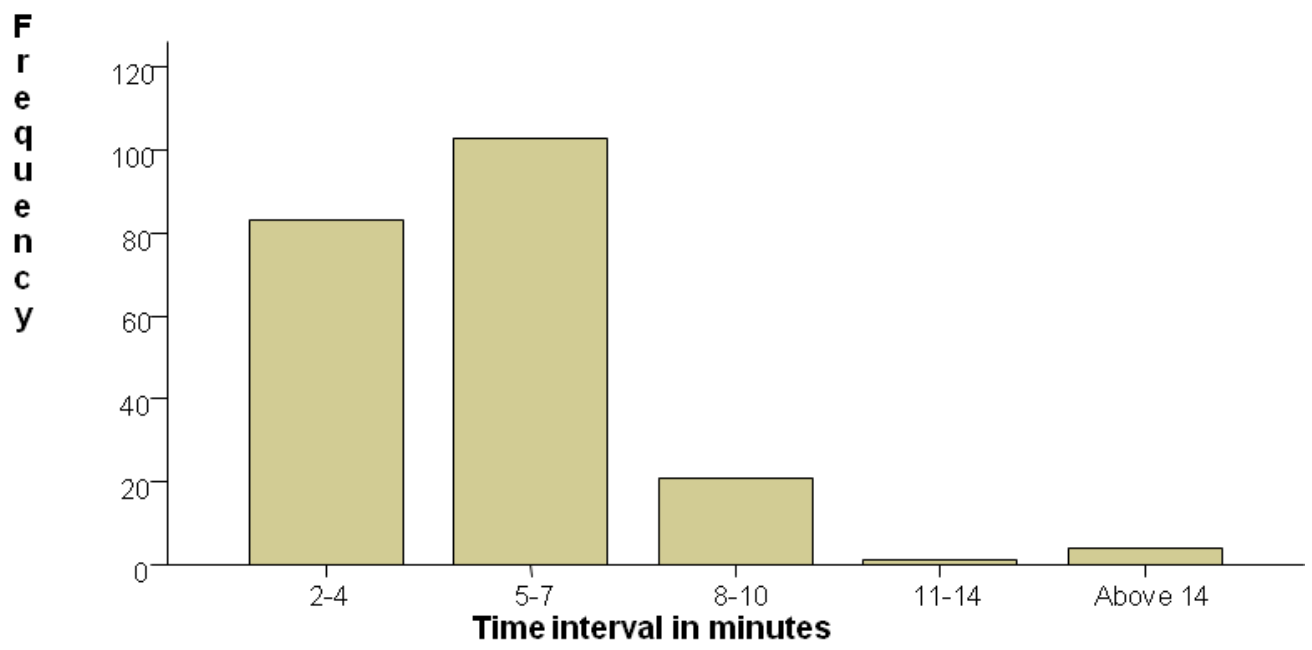

Figure 2: Frequency chart of biomedical examination time, Tikur Anbessa Hospital, November 2009

Table 3 shows the distribution of time for interaction across categories with actual and expected counts. Pearson's Chi square test was used to seek statistical variation and showed no significant variation $(\mathrm{p}=0.112)$, while there was a statistically significant variation for the biomedical exam time $(\mathrm{p}=0.006)$. 
Table 3: Time spent for psycho-social interaction by physician category, Tikur Anbessa Teaching Hospital, November 2009

\begin{tabular}{|c|c|c|c|c|c|c|}
\hline \multirow{2}{*}{ Category } & \multicolumn{6}{|c|}{ Time of interaction in minutes } \\
\hline & $2-4$ & $5-7$ & $8-10$ & 11-14 & $>14$ & Total \\
\hline \multirow[t]{2}{*}{ Intern } & 2 & 28 & 14 & 4 & 3 & 51 \\
\hline & 1.7 & 24.5 & 20.3 & 1.5 & 3.0 & 51.0 \\
\hline \multirow[t]{2}{*}{ Resident } & 3 & 54 & 42 & 2 & 6 & 107 \\
\hline & 3.6 & 51.4 & 42.6 & 3.1 & 6.2 & 107.0 \\
\hline \multirow[t]{2}{*}{ Consultant } & 2 & 17 & 26 & 0 & 3 & 48 \\
\hline & 1.6 & 23.1 & 19.1 & 1.4 & 2.8 & 48.0 \\
\hline \multirow[t]{2}{*}{ Total } & 7 & 99 & 82 & 6 & 12 & 206 \\
\hline & 7.0 & 99.0 & 82.0 & 6.0 & 12.0 & 206.0 \\
\hline
\end{tabular}

$\mathrm{X}^{2}=12.9 ; \quad \mathrm{P}=0.1$

As shown in table 4 , the mean (SE) for psycho-social interaction time was $7.8(0.20)$ minutes while the biomedical examination mean time was $5.05(0.16)$ minutes and the difference noted was significant $(\mathrm{p}=0.001)$. The paired sample correlation was 0.60 $(\mathrm{p}=0.001)$.

Table 4: Paired sample test for time spent on psycho-social interaction and biomedical examination, Tikur Anbessa Hospital, November 2009

\begin{tabular}{|c|c|c|c|c|c|}
\hline Characters & Mean & S.E & $\begin{array}{l}\text { Mean } \\
\text { difference* }\end{array}$ & Correlation* & $95 \% \mathrm{Cl}$ \\
\hline & 7.88 & 0.20 & 2.83 & 0.60 & 2.5 to $0.3-1$ \\
\hline $\begin{array}{l}\text { Psycho-social interaction time (minutes) } \\
\text { Biomedical exam time (minutes) }\end{array}$ & 5.08 & 0.16 & & & 2.5 to $0.3-1$ \\
\hline
\end{tabular}

$\mathrm{Cl}=$ confidence interval; $\mathrm{t}=16.9 ;{ }^{*} \mathrm{p}=0.001$

When time spent for psychosocial interaction and biomedical examination was seen across departments, the frequency distribution showed 54(25.1\%) for obstetrics/gynaecolgy, 48(22.3\%) for internal medicine, $54(25.1 \%)$ for paediatrics and 59 (27.4) for surgery. Average time for psycho-social interaction for each department showed 7.44 minutes for obstetrics/gynaecology, 6.17 minutes for internal medicine, 7.60 minutes for pediatrics and 9.86 minutes for surgery with the total average of 7.88 minutes. The variations between the means across departments was statistically significant $(\mathrm{P}=0.001)$.

Average time for biomedical exams across departments showed shorter duration with gynaecology/obstetrics spending 4.31 minutes, internal medicine 3.77 minute, pediatrics 5.57 minutes and Surgery 6.23 minutes. The total average is 5.07 minutes and the mean variations observed were statistically significant across departments $(\mathrm{P}=0.001)$.

\section{Discussion}

The introduction part of the checklist showed very low ratings for interns, residents, and consultants alike indicating that behavior during interaction was rather poor. Ratings for the body part of the checklist appeared barely satisfactory for all.

The explanation parts of the checklist scores were satisfactory for all categories indicating fair communication efforts by all.
The conclusion part of the score showed very poor ratings for interns and residents (trainees) and was barely satisfactory for consultants. The assumption inferred from this was that physicians did not give attention to reassurance, comfort and imparting hope to their patients at the end of their interaction.

The overall score rating showed poor for interns and barely satisfactory for residents and consultants indicating a clear deficiency in communication skills and behavior.

Current knowledge and research findings in the literature attach more importance to empathy, and behavior towards patients' psycho-social problems than biomedical problems as evidenced in patient centered studies (9-14). Although this study used only providerdefined measuring tools and was not combined with patient-perceived quality measures, the findings still showed similar behavior deficiencies seen in other studies $(7,8)$.

The fact that all categories of physicians scored rather dismally in nearly all items of the checklist reflect that due attention has not been given to the communication skill and behavior part of doctors' training. As the study was conducted in a teaching hospital, the results obtained showed that medical training as it stands to date does not bear any influence on the communication skill and behavior of physicians and their trainees implying the possibility that the problem may be wide spread in medical practice across the nation as a result of the 
deficiency in the medical curriculum. Mean scores of each group of checklist items analyzed within each category showed no statistically significant variation obviating the fact that the problem is uniform across all categories. However, total score analysis showed that differences in the category means were statistically significant which may be explained by other factors not included in the study.

Analysis of interaction time for psychosocial exchange showed $87 \%$ of the interactions were in the $5-7$ minute and in the 8 - 10 minute intervals. Similarly, time spent for biomedical exam showed $86.5 \%$ in the $5-7$ minute and in the 2 - 4 minute groups.

Although there are no universally agreed upon standard time limits for interaction or physical examination; most researchers advocate that more time improves quality of care both from the doctor's and patient's perspectives, while some favor factors associated with doctors' specialty and style of work (23).

A Spanish study found average interaction time for family doctors to be 7 minutes while specialty doctors spent 12 minutes on the average (8). Dutch doctors averaged 10 minutes falling within the European range of $7-16$ minutes in contrast to US- doctors with an average of 17 minutes. Biomedical interaction constituted a quarter of the total time in the Dutch and American observations (23).

The vast majority of interactions fell in the 5-7and 8-10 minute intervals with averages of 8.77 minutes for psychosocial interaction and 5.05 minute for biomedical exam time. Although comparison with above studies is not possible owing to study settings (inpatient against outpatient), country distinction, health care system characteristics, culture, training and philosophy; the average time is slightly lower for both encounters when considering the European and American figures shown above.

Average times for both encounters across departments showed significant variations with surgery taking the longest time in both instances and internal medicine the shortest time. Explanation for this has to be sought in future investigations. The average time for the surgical department does not show whether the visit during observation was pre- or post surgery. This too has to be a matter of further exploration.

The study offers a simple, direct and easy- to -use checklist with a reliable content validity, yet has a number of limitations and shortcomings. Reliability test of observed checklist items was not done as evaluators' observations were not correlated since each evaluator observed interactions as a one-off encounter.
Concurrent validity using other similar measurement scales was not done, and in addition to this, patient's perception was not studied.

Bias both from the observer and observed would inherently affect outcome, and in the absence of audiovisual cross-check, it would be impossible to ascertain validity. Because of its dichotomous nature, the study could not measure quality.

Patients' educational status, social and economic backgrounds had not been appraised, but are known to affect physicians' behavior towards patients (8).

\section{Conclusion}

The medical practice at TASH shows palpable communication skill deficiency among all categories of physicians. We believe TASH and the Medical Faculty should take the lead towards addressing the problem through curricular review and other relevant approaches at institutional level.

Medical education authorities should find ways to improve medical curricula and include the art of communication and proper behavior.

Physicians' deficiency in communication skills and its impact on health outcome should be addressed by health authorities.

Further study by the scientific community is recommended.

\section{Acknowledgments}

We express our thanks to Professor Betsy Bradley and Jeannie Mantopolous from Yale School of Public Health and Lillian Kidane from the Clinton Foundation for providing valuable ideas and references.

Our thanks also go to Professor Mesganaw Fantahun from the School of Public Health, AAU, and Dr Frew Lemma, School of Public Health, London South Bank University.

Finally, we extend our sincere appreciation for the hospital staff, and patients.

\section{References}

1. Accreditation Council for Graduate Medical Education (ACGME). Advancing Education in interpersonal and Communication Skills (an educational resource outcome Project), 2005.

2. Kalet A, Pugnaire M, Cole-Kelly K, Janicik R, Ferrara E, Schwartz M, Lipkin. M, Lazare A. Teaching Communication in Clinical Clerkships: Models from the Macy Initiative in Health Communications, Acad Med 2004;79:511-520.

3. Participants in the Bayer-Fetzer Conference on Physician-Patient Communication in Medical Education. Essential Elements of Communication in Medical Encounters: The Kalamazoo Consensus Statement. Acad Med 2001;76(4):390-393.

Ethiop J Health Dev 2011;25(1) 
4. Colman DR. Bedside manner; A practical guide to interacting with patients (text). First Edition. Anchorage: Alaska; 2007.

5. Windish DM, Price EG, Clever SL, Maaziner JL, Patricia AT. Teaching medical students: The important connection between communication and clinical reasoning; Journal of General Internal Medicine 2005;20:1108- 1113.

6. Travaline JM, Ruchinskas R, D’Alonzo GE. Patientphysician communication: Why and how? Journal of American Ostheopathic Association (JAOA) 2005;105(1).

7. Ashbury FD, Iverson DC, Kralji B. Physician communication skills: Results of a survey of general/family practitioners in Newfoundland. Med Educ. Online (serial online) 2001;6:1: available at URL http://www.med-ed-online.org

8. Ruiz MR, Rodriguez EP, Torres LP, Torre. Physician-patient communication: A study on the observed behaviors of specialty physicians and the ways their patients perceive them; patient Education and Counseling, Elsevier, WWW.elsevier.com/ locate/pateducou : 2006;64:242-248.

9. Falvo D, Smith JK. Assessing residents behavioral science skills: Patient's view of physician-patient interactions. Journal of Family Practice 1983;17(3): 478-483.

10. Doyle BL, Ware JE: Physician conduct and other factors that affect consumer satisfaction with medical care: Journal of Medical Education 1977;52:793-801.

11. Ben SZ. The function of the professional's affective behavior in client satisfaction: A revised approach to social interaction theory. Journal of Health Social Behavior 1976;17:3-11.

12. Coombs RH, Vincent CE. Psycho-social aspects of medical training (text). Chicago, IL: Charles Thomas; 1971.
13. Pacoe LY, Naar R, Guyett IPR, Wells R. Teaching medical students interpersonal relationship skills. Journal of Medical Education 1976;51:743-750.

14. Hutter M, Dungy CL, Zakus GE, Moore VJ, Ott JE, Favert AC. Interviewing skills; A comprehensive approach to reaching and evaluation. Journal of Medical Education 1977;52: 328-333.

15. Suzanne MK. Doctor-patient communication: Principles and practices. Canadian Journal of Neurological Sciences 2002;29:523-529.

16. Duggan A. Understanding interpersonal communication across health contexts: Advances in the last decade and challenges for the next decade. Journal of Health Communication 2006;11: 93-108.

17. Lehmann F, Luke C, Andre B, Dennis F. Physicianpatient interaction: A reliable and valid checklist of quality. Canadian Family Physician 1990;36:17111716.

18. Lebow JL. Consumer assessments of the quality of medical care. Med Care 1974;12:328.

19. Di Matteo MR, Di Nicola D. Sources of assessment of physician performance; A study of comparative reliability and patterns of interaction. Med Care 1981;19:829.

20. Bensing JM; Doctor-patient communication and the quality of care; Soc Sci Med 1991;32(11):1301-1310.

21. Stewart M, Brown J, Levenstein J, McCracken E, McWhinney JR. The patient-centered clinical method: Changes in residents performance over two months of training. Family Practice 1986;3:164-167.

22. Kraan HF, Crijnen AM, Zuidweg J; The Maastricht history-taking and advising checklist (MHAC). Maastricht: The Netherlands, Department of Social Psychiatry, Maastricht Medical School University of Limburg; 1986

23. Bensing JM, Debra LR; Communication pattern of physicians in the United States and the Netherlands. Journal of General Internal Medicine 2003;18: 33534. 